\title{
Glyphosate: Application And Production Ways
}

\section{K.T.ZHANTASOV ${ }^{1}$, S.SH.SHALATAEV ${ }^{1}$, A.A.KADIRBAYEVA ${ }^{1}$, D.M. ZHANTASOVA ${ }^{1}$, ZH.K. DZHANMULDAEVA ${ }^{1}$, B. ISMAILOV ${ }^{1}$ and I.A.PETROPAVLOVSKY ${ }^{2}$}

\author{
${ }^{1} \mathrm{M}$. Auezov South Kazakhstan State University, Kazakhstan, Shymkent. \\ ${ }^{2}$ D.I. Mendeleev Russian Chemical Technological University, Russian Federation, Moscow. \\ ${ }^{\star}$ Corresponding author E-mail: serikoil @ mail.ru
}

http://dx.doi.org/10.13005/ojc/330339

(Received: April 15, 2017; Accepted: May 22, 2017)

\begin{abstract}
The consequences of the harmful effects for plant crops caused by weeds are varied. At the stage of concentration and specialization of the various sectors of the economy the role of plant protection products increases. There is presented the data for use in agriculture and the agricultural sector of economy of glyphosate and various methods for its preparation. Showed materials about the source of raw materials and their properties used in the production of yellow phosphorus and phosphorus three chloride from natural raw materials. Phosphorus is a very common element, derived from phosphate rock and apatite by electro thermal method. On this basis and phosphorus derivatives formed the chemistry of the synthesis process of glyphosate using iminodiacetonitrile and provides basic technological scheme of production of yellow phosphorus and glyphosate. The information submitted by perfecting of technological process of glyphosate receiving by the use of waste of MAP synthesis and indicated ways to improve the environmental issues of production by involving retour. One of the most modern herbicides, which acts selectively and widely used in the agricultural and private sectors are organic phosphorus compounds. Diseases of plant crops, and clogging weeds have a negative impact on their productivity. Basic information on chemism occurring in the preparation of glyphosate, its generalized form, the overall reaction in the presence of catalysts are given.
\end{abstract}

Keywords: herbicide, glyphosate, phosphorus, trichlorophosphorus, iminodiacetonitrile, total reaction.

\section{INTRODUCTION}

At the present stage of industrial development a role of fungicides, pesticides, insect of fungicides and seed treatment reagents intended for protection of crops and green plantations from illnesses and weeds essentially increases.
It is necessary to notice, that crop and green plantation illnesses and weed spreading can arise even before a harvest or after ripening of seeds. Therefore, the treatment of young growth and seeds during the ripening is a basic method of illness control and weed abolition and decrease in their germination. 
Many inorganic compounds are widely applied as pesticides, insecticides, herbicides, phytohormones, fungicides and other preparations in many countries. One of the most important classes of the modern pesticides, widely used in rural and subsidiary sectors of economy, is organic compounds of phosphorus with various physiologically active substances, which have selective action. The given class also includes acaricides, insecticides, phytohormones and other phosphorus derivatives capable pesticide properties ${ }^{1}$.

One of the herbicides of selective and continuous action applied for spraying is glyphosate with a wide spectrum of activity. Glyphosate can be applied for abolition and growth suppression of annual and perennial weeds on the fields intended for sowing various crops. It can be used on grape and tea plantations, at planting of citrus and fruit trees, in personal subsidiary and water farms, in forest tree nurseries for directional soil spraying or at the repeated use of some herbicides.

A chemical formula of glyphosate is $\mathrm{C}_{3} \mathrm{H}_{8} \mathrm{NO}_{5} \mathrm{P}$; it is an organo phosphorous compound [N-(phosphonomethyl)-glycine], which has the following chemical structure:<smiles>O=C(O)CNCP(=O)(O)O</smiles>

Glyphosate has the following synonyms - raundape, glycele, glytane, glyalca, glyssole, glyphonine, glycale, nitrosorg, intosorg, utal, phorsate, phosulene, cydocore ${ }^{2-4}$.

These are white odorless well water-soluble granules or crystals. They are very poorly soluble in organic solvents; at the interaction with organic bases glyphosate forms salts easily soluble in water. With the chemical point of view ${ }^{5}$ glyphosate is a weak organic acid.

For increase in solubility of the preparations, glyphosate is turned into potassium, ethanolamine, dimethylamine, ammonium or isopropylamine salts.
The majority of glyphosate- based herbicides contain an isopropyl salt as a reactant ${ }^{4}$ :

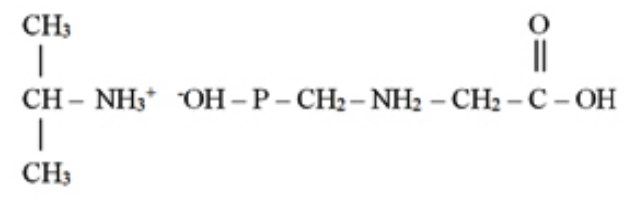

Abroad glyphosate is used for production of tank mixtures with ala-chlorine, atrazine and simazine, linurone, metribyzine, etc.

In accordance with ${ }^{6}$, at production of glyphosate on the basis of iminodiacetonitrileby the third way the initial raw components are yellow phosphorus, trichlorophosphorus, formaldehyde and a $32 \%$ sodium hydroxide solution.

A schematic circuit of glyphosate production in accordance with the above-mentioned method is represented in the figure 1.

In Kazakhstan the LP "Kazphosphate" produces phosphorus from local natural raw material - phosphorites of the Karatau field. This phosphorus can be used for the glyphosate manufacture.

Phosphorus is rather a widespread element; about $0,04 \%$ of the general number of the atoms forming the earth crust are phosphorus atoms. Phosphorus is a part of some proteic substances of nerve and brain tissues and human and animal bones; it has an important value for vital activity of living organisms.

Amain raw material for phosphorus manufacture isphosphorites and apatites, which contain a mineral $\left[\mathrm{Ca}_{5} \mathrm{O}\left(\mathrm{PO}_{4}\right)_{3}\right.$, where O - is fluorine $\left(\mathrm{F}^{-}\right)$, a hydroxyl group $\left(\mathrm{OH}^{-}\right)$and sometimes chlorine $(\mathrm{Cl})$ ], and also various impurities.

Elemental phosphorus is produced by an electrothermal way at temperatures of $1350^{\circ} \tilde{N}$ and above from natural phosphorites in the presence of quartzite as a flux and metallurgical coke as a reducer; all the components are taken in certain ratios.

A schematic circuit of the phosphorus production is represented in the figure 2 . 
The process occurs in accordance with the following total reaction (nonmetering impurities):

$$
\mathrm{Ca}_{3}\left(\mathrm{PO}_{4}\right)_{2}+3 \mathrm{SiO}_{2}+5 \mathrm{C}=3 \mathrm{CaSiO}_{3}+5 \mathrm{CO}+2 \mathrm{P}
$$

The gaseous phosphorus formed in an ore-thermal furnace is purified from the dust in electrostatic precipitators, condenses in "hot" and "cold" condensation towers and flows down in phosphorus water-filled tanks ${ }^{11}$. The phosphorus produced by this way is named white or yellow phosphorus.

At storage the white phosphorus gradually turned into more stable red phosphorus with heat liberation.

The transition of white phosphorus in a red form is accelerated by long heating in a hermetically sealed reactor at temperatures of $280-340^{\circ} \mathrm{C}$. Red phosphorus represents a powder, which vapours condense and again turn in white phosphorus. This phosphorus can be used for trichloro phosphorus manufacture, which by-turn is the raw material for glyphosate production.
Obtaining of trichlorophosphorus can be fulfilled by a very simple way ${ }^{7-10}$, namely, by phosphorus chlorination using an installation represented in the figure 3 . The phosphorus chlorination occurs on the reaction:

$$
2 \mathrm{P}+3 \mathrm{Cl}_{2}=2 \mathrm{PCl}_{3}
$$

For reduction of the phosphorus chloride losses at evaporation a receiver is attached to a back flow condenser. The process is carried out paying special attention for the chlorine feed rate, the phosphorus heat and the immersion depth of a gas-intake tube in a retort. It is necessary for the exclusion of a deposition on a reactor wall, which forms at a violent reaction of trichloro phosphorus synthesis, as at the chlorine excess and the insufficient phosphorus temperature it is possible formation of phosphorus pentachloride.

Trichloro phosphorus is a colourless liquid fuming in damp air, which forms chloro-anhydride of phosphorous acidat interaction with water.

For glyphosate manufacture except the above mentioned raw materials the following

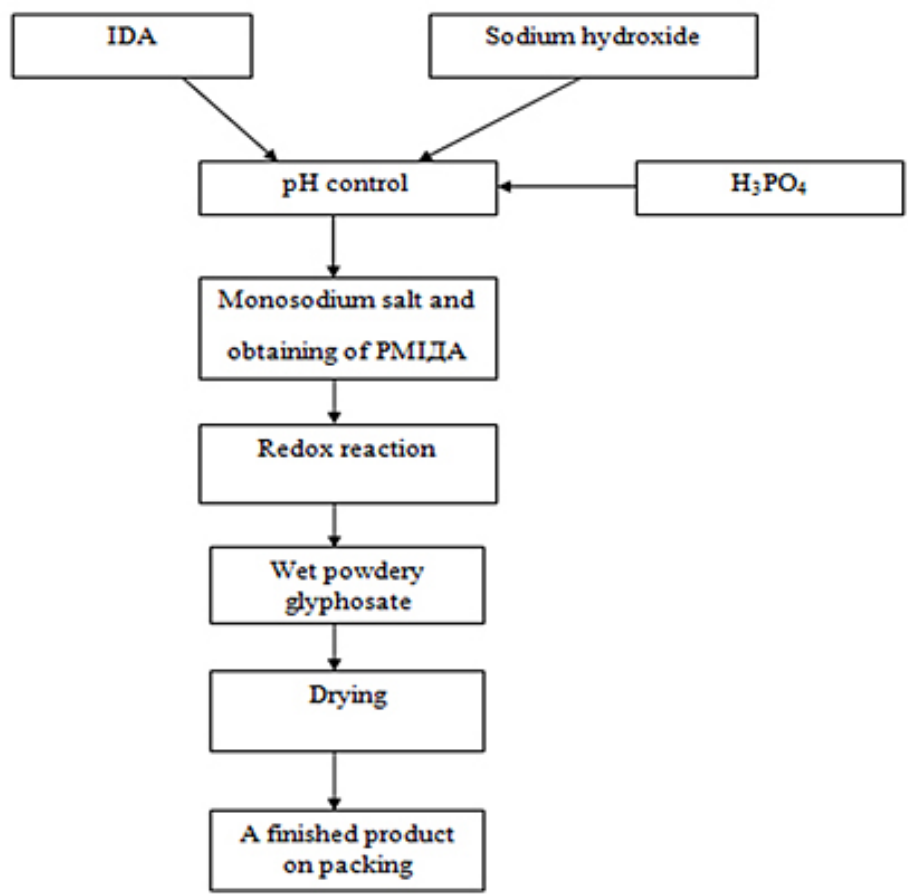

Fig. 1: A schematic circuit of glyphosate production 


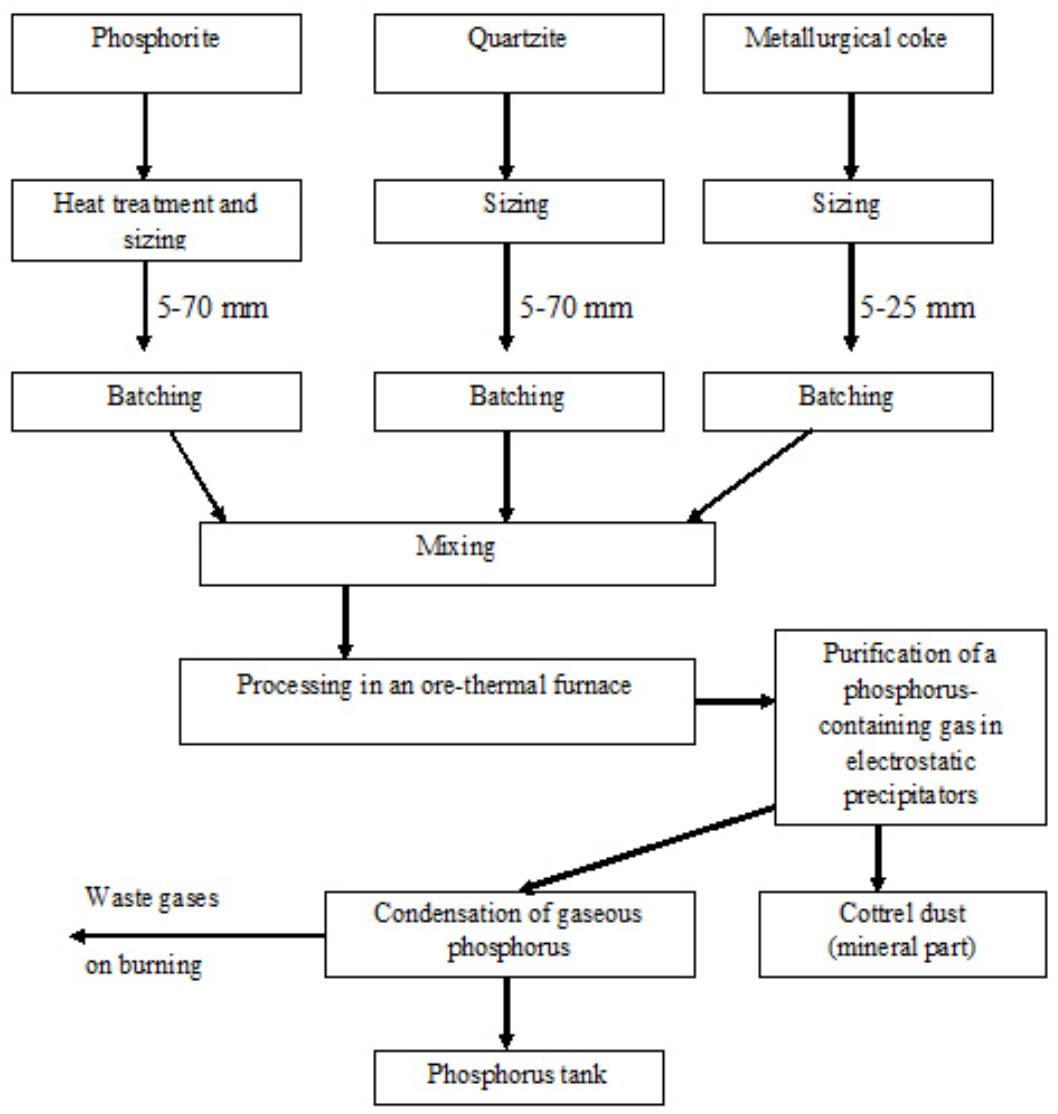

Fig. 2: Aschematic circuit of the phosphorus production from natural mineral raw materials and metallurgical coke in ore-thermal furnaces

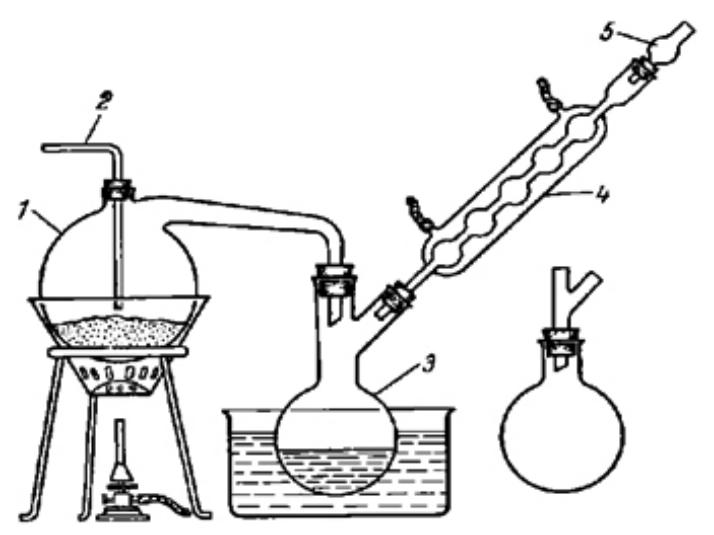

Fig. 3: An installation for trichlorophosphorus obtaining:

1. A retort with a cone holder

2. a gas-intake tube

3. a receiver

4. a backflow condenser

5. a calcium-chloride tube compounds can be applied: iminodiacetonitrile, formaldehyde, hydrogen peroxide, sodium hydroxide and hydrochloric acid.

Iminodiacetonitrile (IDAN) is obtained by the preparation of a water mixture of hexamethyl tetramine, cyanic hydrogen, sulfuric acid or other acids such as hydrochloric or nitric ones; $\mathrm{pH}$ of the mixture prepared should be within 3-5 at a certain ratio of hexamethyl tetramine and cyanic hydrogen. Then the mixture is passed through a tubular reactor; a temperature in a reaction zone must be from 50 to $150^{\circ} \mathrm{C}$.

Imino diacetonitrileenters into a reaction with aqueous solutions of sodium hydroxide and hydrochloric acid and forms ammonia and sodium imino diacetate, which interacts with atrichloro phosphorus water solution and formaldehyde and changes into phosphonomethyl iminodiacetonitrile 

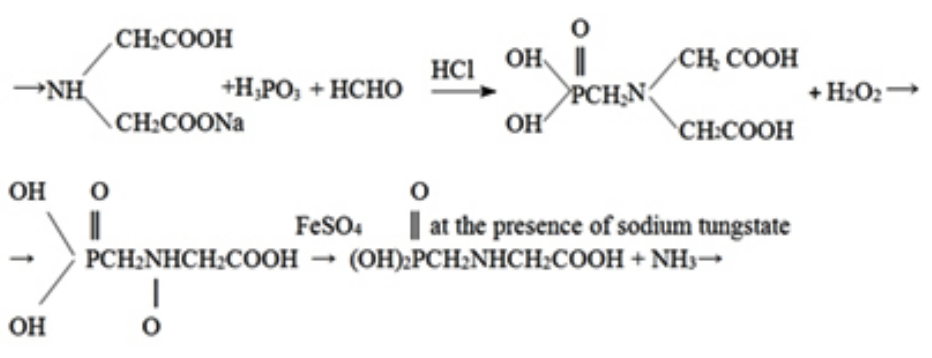

$$
\begin{aligned}
& \text { o } \\
& \text { I } \\
& \rightarrow(\mathrm{OH})_{2} \mathrm{PCH}_{2} \mathrm{NHCH}_{2} \mathrm{COONH}_{4}
\end{aligned}
$$

\section{Fig. 4: The reactions in the process of glyphosate synthesis}

(PMIDA). Then PMIDA enters into a redox reaction with hydrogen peroxideandiron sulphate in a water medium in the presence of sodium tung state as a catalyst and forms glyphosate. The product obtained is concentrated, is subjected to membrane separation before the formation of $10-20 \%$ of a glyphosate aqueous solution and is treated by ammonia for the further obtaining of ammonium glyphosate. The process of glyphosate synthesis can be described the following summarized reaction:

The products of this total reaction are ammonia, water, and sodium chloride.

Trichloro phosphorus is a necessary component for manufacture of phosphorous acid H3PO3used for the PMIDA synthesis at the presence of formaldehyde. In addition, in the redox reaction of PMIDA with hydrogen peroxide it is necessary to use a catalyst - sodium tung state and iron sulphate.

The by-products of the total reaction after purification and regeneration can be used in other technological processes; it allows deciding environmental questions of the manufacture.

A mass fraction of glyphosate in the finished product should be $95 \%$ and above.

For the purpose of improvement of the production effectiveness and the glyphosat equality it is necessary to continue the researches connected with use of ammophos on the last stage - the neutralisation of a $10 \%$ aqueous glyphosate solution by a gaseous ammonia.
The obtained product, as it has been specified above, is a sterilizing and absorbing herbicide with low toxicity and has a wide action spectrum.

For a purpose of improving the glyphosate production technology it is supposed instead of phosphorus trichloride to use the subquality ammophos contained simultaneously nitrogen and phosphorus, basic components for the synthesis of $\mathrm{N}$-phosphorus methyl glycine.

\section{CONCLUSIONS}

1. The conclusion on the use of the compounds of inorganic substances in various industries, including the manufacture of pesticides and herbicides such as glyphosate and used on plant protection and weed control.

2. Identified Raw Materials for the production of glyphosate by iminodiacetonitrile using elemental yellow phosphorus, phosphorus trichloride, formaldehyde, mononatrium salts and tung state of natrium such catalyst.

3. Based on the various methods of producing glyphosate showed summarizes chemise synthesis of finished product by reaction with the formation of ammonia, sodium chloride and water. It proposed to use as nitrogen and phosphorus-containing product in the ammonia synthesis, MAP return detail, allowing to improve the process and to improve the economic condition of the industrial enterprise.

4. Introduction of MAP returns must perform in the neutralization step of $10 \%$ aqueous solution of glyphosate with ammonia gas. 


\section{REFERENCES}

1. Zhantasov, K.T.; Shalataev, S. Sh.; Zhantasov, M. K.; Kalymbetov, G. E. IV International Theoretical and Practical Conference, 2015, 2, 164.

2. Khamitova, R.; Mirsaitova, G. T. J. Hygiene and sanitation. 2014, 4(93), 23-26.

3. Turusov, V. S.; Rakshitsky, V. N.; Sinitcina, G. A. Review of the herbicides market in the CIS. Moscow. 2008, 87-80.

4. Kuznecova, E. M.;Chmil,V.D. J. Modern problems of toxicology. 2010, 1(48), 87-95.

5. Zhantasov, K. T.; Shalataev, S. Sh.; Kadirbaeva, A. A.; Alteev, T. A.; Zhantasov, M.K.; Zhantasova, D.M.; Kocherov, E.N. Modern condition and prospects of glyphosate manufacture. J. Modern high technologies, 2014, 12,156-159.
6. V. A. Miliukov, Y. G. Budnikova, O. G. Sinyachin. Russian Chemical Reviews, 2005, 74 (9), 859-885.

7. Israilov, A.A. Directions of development of the chemistry and technology of production of fungicides and seed disinfectants (Doctoral dissertation). Retrieved from http://fizmathim. $\mathrm{com} /$ napravleniya- razvitiya-himii-i-tehnologiiproizvodstva-fungitsidov-i-protraviteleysemyan, 2007.

8. www.infomine.ru

9. Greenwood, N.; Ernsho, A. Moscow: Binom. Laboratory of knowledge, 2008, 1, 598.

10. Zhantasov, K.T.; Aibalaeva, K.D.; Frangulidi, L.H.; Barlybaev, M.R.;Berzhanov, D.S.; Yurchenko, B.N.; Zhantasov, M.K. Almaty: Evero, 2014, 444. 